See discussions, stats, and author profiles for this publication at: https://www.researchgate.net/publication/234123226

\title{
Is There Evidence for Cognitive Intervention in Alzheimer Disease? A Systematic Review of Efficacy, Feasibility, and Cost-Effectiveness
}

Article in Alzheimer disease and associated disorders · January 2013

DOI: 10.1097/WAD.0b013e31827bda55 · Source: PubMed

\section{CITATIONS}

28

6 authors, including:

Jorge Alves

CEREBRO - Brain Health Center

21 PUBLICATIONS 192 CITATIONS

SEE PROFILE

(1)

Oscar F Goncalves

University of Minho

202 PUBLICATIONS 1,690 CITATIONS

SEE PROFILE

Some of the authors of this publication are also working on these related projects:

Emotional Movie Database (EMDB) View project

Project Applied Neuroscience Research View project
A Rosana Magalhães

Centro Clínico Académico (2CA-Braga)

17 PUBLICATIONS 141 CITATIONS

SEE PROFILE

Agavni Petrosyan

University of California, Irvine

17 PUBLICATIONS 182 CITATIONS

SEE PROFILE 


\title{
Is There Evidence for Cognitive Intervention in Alzheimer Disease? A Systematic Review of Efficacy, Feasibility, and Cost-Effectiveness
}

\author{
Jorge Alves, MSc,* Rosana Magalhães, MSc,* Roger E. Thomas, MD, PhD, $\dagger$ \\ Óscar F. Gonçalves, PhD, * Agavni Petrosyan, PhD,* and Adriana Sampaio, PhD*
}

\begin{abstract}
Several studies have shown that cognitive intervention may be beneficial for people with Alzheimer disease (AD), but literature reviews conducted so far, have yielded mixed and inconclusive results.

In this work, through an extensive bibliographic search, we aim: (1) to analyze the efficacy of cognitive intervention in patients diagnosed with $\mathrm{AD} ;(2)$ to provide an estimate of the feasibility of cognitive intervention; and (3) to review available cost-effectiveness data of this approach.

Four randomized controlled trials of cognitive intervention, for patients diagnosed with $\mathrm{AD}$ that incorporated cognitive intervention and mock intervention control conditions, were included in the analysis. Only the domain of global cognitive functioning, as measured by Mini-Mental State Examination, showed significant intervention effects. No effects were observed in the remaining domains. Concerning feasibility, high rates of completion and adherence were found. A single randomized controlled trial, with unspecified dementia, suggested cognitive intervention to be cost-effective.

Given the currently available dearth of well-controlled and focused trials in $\mathrm{AD}$, these results should be carefully interpreted and remain to be confirmed in the future. There is a clear need for more high-quality research.
\end{abstract}

Key Words: Alzheimer disease, cognitive intervention, cognitive stimulation, cognitive rehabilitation, cognitive training, cost-effectiveness

(Alzheimer Dis Assoc Disord 2013;00:000-000)
A lzheimer disease (AD) is a neurodegenerative disorder that progressively affects cognitive and social functioning and accounts for at least $60 \%$ of cases of dementia. ${ }^{1}$ The most impaired function in $\mathrm{AD}$ is episodic memory, with relative sparing of semantic and procedural memory in the early stages of the disease. ${ }^{2}$ However, for the early stages of the illness, there have been increasing evidence of mild deficits in the cognitive domains of executive function, verbal ability, visuospatial ability, attention, and perceptual speed. ${ }^{3}$

The standard treatment for improving cognition in AD participants consists of antidementia drugs, even though this typical treatment has shown limited efficacy 4,5 and, therefore, nonpharmacological interventions ${ }^{6}$ have been considered as a complementary option of intervention.

In the context of psychosocial interventions, cognitive interventions focus on the improvement or maintenance of cognition and patient functioning, using 3 prototypical approaches $^{2}$ : (1) cognitive stimulation, in which the patient participates in group discussions aimed at improving cognition and social functioning; (2) cognitive training, such as memory exercises in paper and pencil or computer format; or (3) cognitive rehabilitation with tailored interventions designed and implemented to address each patient's key difficulties and goals.

Previous meta-analyses ${ }^{7,8}$ display mixed findings regarding the efficacy of cognitive interventions. First, conclusions were based on both randomized controlled trials (RCTs) and nonrandomized studies. ${ }^{8}$ Second, mixed samples of $\mathrm{AD}$ and other dementias were also included in the analyses. $^{7,8}$ Third, although noncognitive placebos are available, such as relaxation training, ${ }^{9}$ or psychoeducation, ${ }^{10}$ previous studies utilized control conditions influencing cognition and therefore diluting the potential effect of the experimental intervention. Thus far, no study of cognitive intervention, for patients with $\mathrm{AD}$, has directly addressed the intervention completion or adherence rates. Costs are also seldom reported despite the strong clinical and economical relevance of these indicators.

The objective of the present review was to summarize all the available high-quality (RCT) studies on cognitive intervention efficacy and feasibility. Furthermore, we aimed to collect cost-effectiveness data pertaining to the cognitive intervention in AD.

In this review (unlike prior published meta-analyses) we excluded mild cognitive impairment, mixed AD, vascular dementia, and other types of dementia such as frontotemporal dementia or dementia with Lewy bodies. We assessed the cost-effectiveness and estimated the feasibility of cognitive intervention by way of considering the rates of completion and adherence to intervention. 


\section{METHODS}

\section{Data Sources and Study Selection}

Eleven databases were searched: PubMed, PsychINFO, The Cochrane Library (Cochrane CENTRAL Register of Controlled Trials), EMBASE, metaRegister of Clinical Trials (ISRCTN Register, NIH ClinicalTrials.gov Register - subset of randomized trial records), OVID all EBM Reviews (Cochrane DSR, ACP Journal Club, DARE, CCTR, HTA, NHSEED) from inception to October 7, 2011 with no limits on language for RCTs of cognitive interventions in AD (PubMed and EMBASE searches were updated on March 16, 2012, yielding no additional relevant results). See Figure 1 (PRISMA flow diagram ${ }^{11}$ ) and Supplementary Table 1, (http://links.lww.com/WAD/A47) for full details of the search.

Inclusion criteria:

(1) The study had to meet the definition of one of the 3 approaches defined by Clare and Woods ${ }^{2}$ : cognitive stimulation, cognitive training, and cognitive rehabilitation. Other therapies, such as reminiscence therapy, psychotherapy, and behavioral or occupational intervention were not considered.

(2) Only RCTs were considered.

(3) Available data from a mock intervention group (placebo condition) had to be reported (ie, cognitive and mock interventions had to be comparable in terms of frequency, duration, and contact with the therapist). Acceptable mock interventions included unstructured or semistructured activities without a focus on cognition or cognitive aspects of social interaction. Although one might argue that it is impossible to eliminate any component of cognition, the aforementioned situations allow minimizing the amount and quality of cognitive component. Cognitive strategies or techniques (eg, imagery) were not considered as mock interventions. Activities not focused on cognition, such as, relaxation training ${ }^{9}$ and psychoeducation, ${ }^{10}$ have been previously used and considered to be appropriate in minimizing the cognitive engagement of the participant and providing viable and ethical options while providing comparable levels of social and/or therapist interaction.

(4) The intervention had to be delivered in an individual or a group format for all the participants. Dyadic formats (patient and caregiver receiving the intervention and being the unit of analysis) were not considered.

(5) The cognitive intervention had to be delivered/directed by a health professional (eg, psychologist, physician, nurse, or social worker) or a member of the research team. Homework exercises supervised by caregivers were allowed. Paper and pencil as well as computerbased exercises were considered.

(6) Available data comparing groups on main characteristics (diagnosis, education, age, global cognitive status) had to be reported.

(7) Available data on pre-intervention and post-intervention measures had to be reported. (Availability of follow-up data was not a requirement for an inclusion in this review.)

(8) Available data had to be sufficient for calculating the effect of the intervention.

Additional studies were also identified from reference lists of retrieved studies. RCTs that focused on cognitive

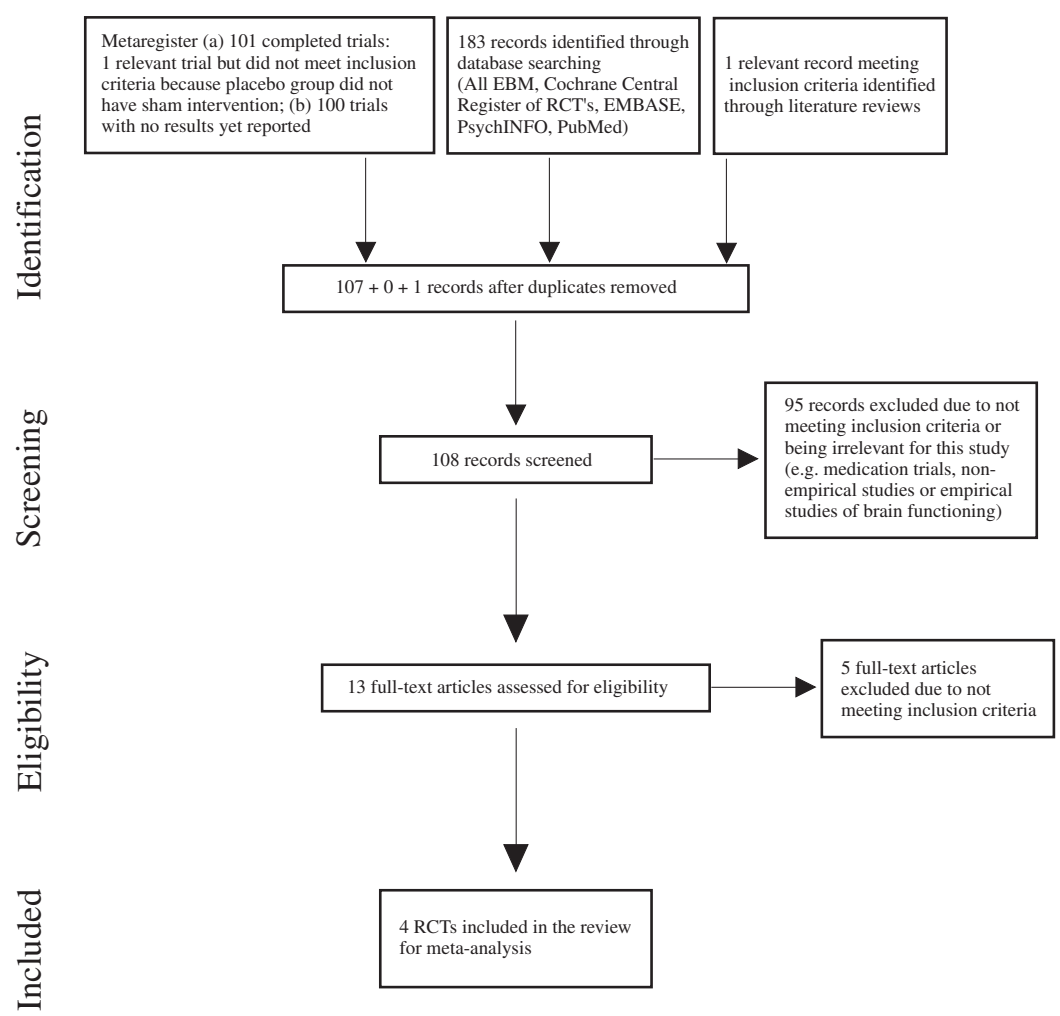

FIGURE 1. PRISMA flow diagram. Flow diagram of the search process. RCT indicates randomized controlled trial. 


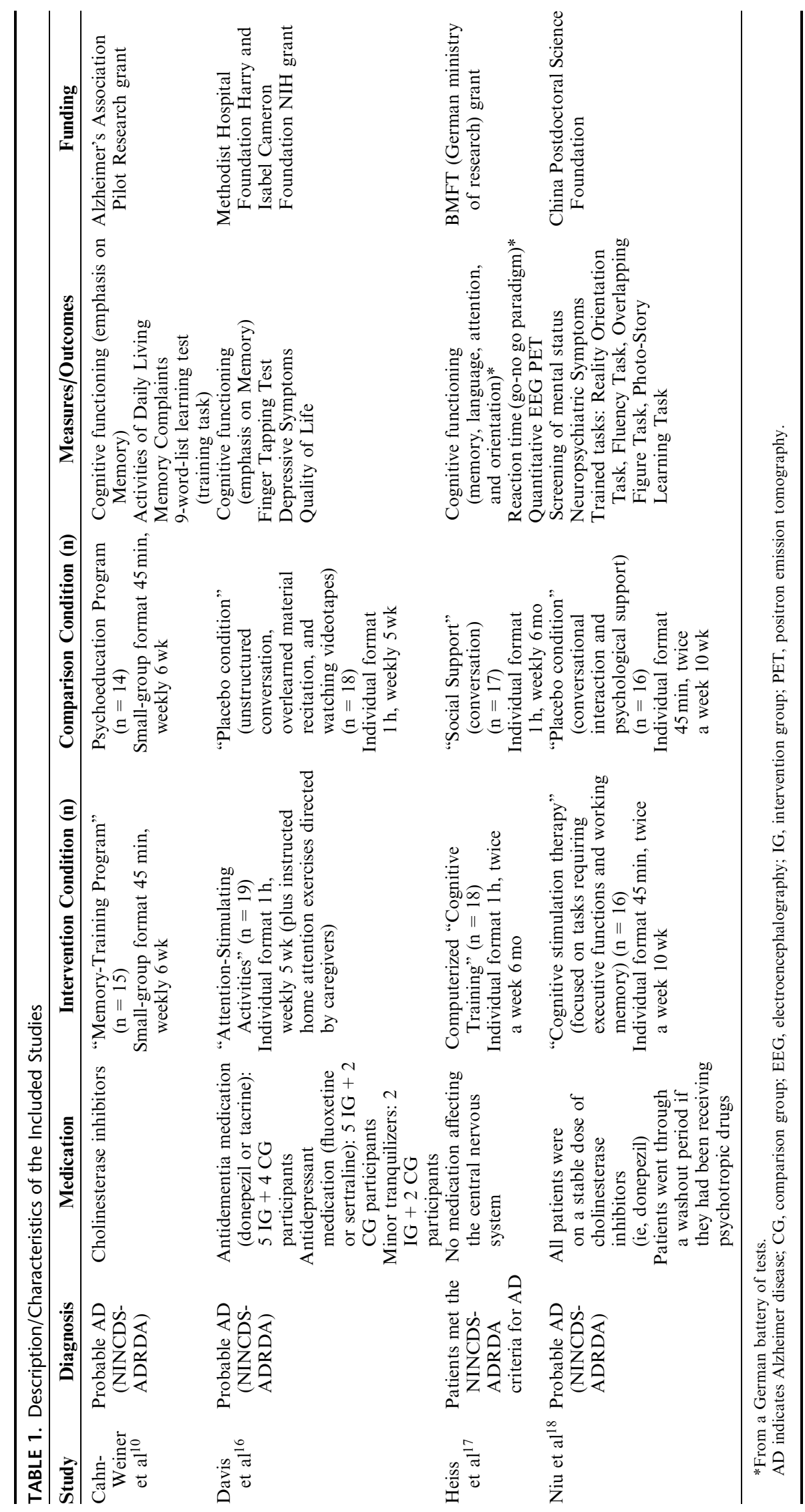


intervention compared with a placebo intervention, in AD patients, diagnosed according to well-established criteria $^{12,13}$ were selected. Therefore, non-empirical studies, behavioral/psychotherapy interventions, or pharmaceutical trials were excluded.

\section{Data Extraction and Data Analysis}

Studies were independently assessed after which data was entered into the Review Manager Software version 5.1 (RevMan 5$)^{14}$ by 2 authors (J.A. and R.M.). All available information on all the neuropsychological, neuropsychiatric, psychomotor, activities of daily living, and quality-of-life measures were collected. In case there was no available information about a specific test or battery (concerning the scale or units of measure), the data were discarded. For each measure, we recorded the mean scores at post-treatment the $\mathrm{SD}$, and the number of patients per group. When available, preference was given to the mean change, from pre-treatment to post-treatment. Only data collected after participants' randomization was included.

For data analysis, the Review Manager Software ${ }^{14}$ version 5.1 for Windows was utilized.

As there was no evidence of heterogeneity (ie, $I^{2}<50$ ) continuous data were analyzed by mean differences using the fixed effects model [with 95\% confidence intervals (CI)].

To provide a meaningful integration of data from different studies, after a detailed inspection of each study results, outcomes were grouped into distinctive domains. When different measures were used for a particular domain the standardized mean difference was employed.

The default setting for the software was a lower value corresponding to a better outcome. The latter default setting was used for measures such as reaction time, assessment of neuropsychiatric symptoms, depression symptoms, or memory complains. As most neuropsychological measures employ higher scores to indicate better performance, forest plot labels were adjusted (ie, inverted) when needed.

Forest plots were then generated for each domain and visual inspection of graphs and $I^{2}$ index were used for assessing heterogeneity and its impact.

For the feasibility analysis, we recorded the number of dropouts after randomization and the reasons for dropping out together with number of missed sessions. The completion rate (percentage of people who completed the program) and adherence rate for each group (percentage of attended sessions of each person divided by the total number of sessions of the program for the entire group) were then calculated.
As none of the retrieved studies reported costs or costeffectiveness data, an additional bibliographic search in PubMed was carried out with the following search terms: dementia, Alzheimer's disease, cognitive intervention, cognitive stimulation, cognitive training, cognitive, rehabilitation, memory training, cost, medical care, expenditures, medical care expenses, cost-effectiveness, and cost benefit. Currencies were systematically updated in view of inflation with the most recent available inflation values according to the Bank of England. ${ }^{15}$

\section{RESULTS}

\section{Included Studies}

The search (Fig. 1) yielded 108 results assessed for suitability according to the inclusion criteria. From these, 95 were excluded because of $\geq 1$ of the following reasons: (a) nonrandomized controlled studies; (b) mixed samples (ie, samples including AD participants and other dementias, mild cognitive impairment, or nonspecified diagnosis of dementia); (c) unequal mock control groups (in terms of duration and frequency); (d) RCTs of pharmacological treatments with no additional psychosocial interventions; e) non-empirical studies; and (f) interventions exclusively delivered by caregivers. From the remaining 13 full-text articles, 4 studies met the full inclusion criteria. ${ }^{10,16-18}$ Further characteristics of the included studies and the respective outcome measures can be found in Table 1. The risk of bias of each study was assessed independently by 2 of the authors (J.A. and R.M.) with the Cochrane risk-ofbias tool, which was assessed as low risk across the 4 analyzed studies (Fig. 2).

\section{Efficacy of Cognitive Intervention}

Outcomes of the included studies were grouped into distinctive domains (Table 2).

Results for cognitive intervention effects are shown in Table 3. Comparisons between the cognitive intervention group and the active control group yielded statistically significant intervention effects in terms of Global Cognitive Functioning [as assessed by the Mini-Mental State Examination (MMSE); see Fig. 3 for Forest and Funnel plots] (mean difference, 0.87; 95\% CI, 0.26-1.48), Neuropsychiatric Assessment/Symptoms (mean difference, - 2.06; 95\% CI, -2.91 to -1.21 ), and Memory Complaints (mean difference $19.90 ; 95 \%$ CI, 1.87-37.93). It is important to note that only 1 study addressed Neuropsychiatric Assessment/ Symptoms and Memory Complaints. No significant

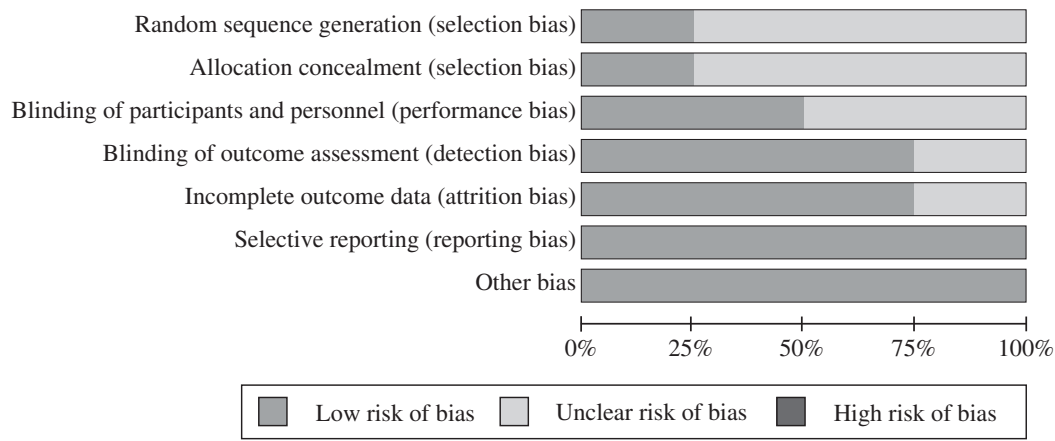

FIGURE 2. Assessment of risk of bias. Assessment of risk of bias of the included studies, based on the Cochrane risk-of-bias tool. 
TABLE 2. Distribution of Tests of the Included Studies Per Different Domains

\begin{tabular}{|c|c|c|c|c|}
\hline Domains & Cahn-Weiner et a ${ }^{10}$ & Davis et al $^{16}$ & Heiss et al ${ }^{17}$ & $\begin{array}{c}\text { Niu } \\
\text { et } \text { al }^{18}\end{array}$ \\
\hline Global Cognitive Functioning & - & MMSE & MMSE & MMSE \\
\hline $\begin{array}{l}\text { Immediate Auditory/Verbal } \\
\text { Memory }\end{array}$ & $\begin{array}{l}\text { HVLT-R Total } \\
\text { Learning }\end{array}$ & $\begin{array}{l}\text { Logical Memory-Immediate } \\
\text { (WMS-R) }\end{array}$ & Verbal Selective Reminding & - \\
\hline $\begin{array}{l}\text { Immediate Visuospatial } \\
\text { Memory }\end{array}$ & $\begin{array}{l}\text { BVMT-R Total } \\
\text { Learning }\end{array}$ & $\begin{array}{l}\text { Visual Reproduction-Immediate } \\
\text { (WMS-R) }\end{array}$ & Corsi Block Span & - \\
\hline $\begin{array}{l}\text { Delayed Auditory/Verbal } \\
\text { Memory }\end{array}$ & $\begin{array}{l}\text { HVLT-R Delayed } \\
\text { Recall }\end{array}$ & $\begin{array}{l}\text { Logical Memory-Delayed (WMS- } \\
\text { R) }\end{array}$ & - & - \\
\hline Delayed Visuospatial Memory & $\begin{array}{l}\text { BVMT-R Delayed } \\
\text { Recall }\end{array}$ & $\begin{array}{l}\text { Visual Reproduction-Delayed } \\
\text { (WMS-R) }\end{array}$ & - & - \\
\hline $\begin{array}{l}\text { Delayed (Auditory/Verbal) } \\
\text { Memory-Recognition }\end{array}$ & $\begin{array}{l}\text { HVLT-R } \\
\text { Recognition }\end{array}$ & - & $\begin{array}{l}\text { Verbal Selective Reminding } \\
\text { Recognition }\end{array}$ & - \\
\hline $\begin{array}{l}\text { Delayed (Visuospatial) } \\
\text { Memory-Recognition }\end{array}$ & $\begin{array}{l}\text { BVMT-R } \\
\text { Recognition }\end{array}$ & - & - & - \\
\hline Working Memory & - & Digit Span Backward (WAIS-R) & - & - \\
\hline Attention and Concentration & TMT A & VSAT & - & - \\
\hline Verbal Fluency_Phonemic & COWA & COWA & - & - \\
\hline Verbal Fluency-Semantic & - & Supermarket & Supermarket & 一 \\
\hline Language - Naming & Boston Naming Test & - & - & - \\
\hline Visuospatial Abilities & JLO & & - & - \\
\hline Motor Speed & - & Finger Tapping Test $-\mathrm{DH}$ & - & - \\
\hline Neuropsychiatric Assessment & - & - & - & $\begin{array}{l}\text { NPI- } \\
\text { Total }\end{array}$ \\
\hline Depressive Symptoms & - & GDS & - & - \\
\hline Quality of Life & - & QLA-P & - & - \\
\hline Activities of Daily Living & ADL questionnaire & - & - & - \\
\hline Memory Complaints & EMQ & - & - & - \\
\hline
\end{tabular}

ADL questionnaire indicates Instrumental Activities of Daily Living and Physical Self-Maintenance Scale (modified version); BVMT-R, Brief Visual Spatial Memory Test-Revised; COWA, Controlled Oral Word Association test; DH, Dominant Hand; EMQ: Everyday Memory Questionnaire; GDS, Geriatric Depression Scale; HVLT-R, Hopkins Verbal Learning Test-Revised; JLO, Judgment of Line Orientation; MMSE, Mini-Mental Status Examination; NPI, Neuropsychiatic Inventory; QLA-P, Quality of Life Assessment-Patient; TMT A, Trail Making Test A; VSAT, Verbal Series Attention Test; WAIS-R, Wechsler Adult Intelligence Scale-Revised; WMS-R, Wechsler Memory Scale-Revised.

intervention effects were found in the majority of domains: Immediate Auditory/Verbal Memory; Immediate Visuospatial Memory; Delayed Auditory/Verbal Memory; Delayed Visuospatial Memory; Delayed (Auditory/Verbal) Memory-Recognition; Delayed (Visuospatial) MemoryRecognition; Working Memory; Attention and Concentration; Verbal Fluency-Phonemic; Verbal Fluency-Semantic; Language-Naming; Visuospatial Abilities; Motor Speed; Depressive Symptoms; Quality of Life; and Activities of Daily Living).

Since only one of the included studies presented follow-up data, no follow-up data were analyzed for the present study.

No evidence of heterogeneity was found (the $I^{2}$ index was always $<50 \% .{ }^{19}$ )

\section{Feasibility of Cognitive Intervention for AD Patients}

The completion rate of the intervention programs ranged from $85 \%$ to $100 \%$. Adherence rates ranged from $96.7 \%$ to $100 \%$ for the intervention group and from $92.9 \%$ to $100 \%$ for the control group (see Table 4 for a detailed description).

\section{Cognitive Intervention Cost-Effectiveness}

Only 1 study was found to provide cost-effectiveness data. ${ }^{20}$ The latter mentioned study researched the effects of a cognitive stimulation program in people with dementia living in care or community homes, while not receiving cholinesterase inhibitors. The estimated cost in 2001 was
$£ 90$ per session ( $£ 73$ for researchers' time, $£ 11$ for care assistant's time, $£ 5$ for travel, and $£ 1$ for equipment). As of 2011, the cost of a cognitive stimulation session was 122.13. As in the above-mentioned study, ${ }^{20}$ the intervention was delivered in a small-group format (ie, 5 participants), in 2001, the cost of an intervention per person per week was $£ 31.50$ ( $£ 42.74$ as of 2011 ). Knapp et $\mathrm{al}^{20}$ found no statistically significant effects between 2 groups under study in terms of service use (residential care, domestic housing, hospital services, day services, community services) or service cost.

The cost-effectiveness analysis, of the aforementioned article ${ }^{20}$ revealed the cost per incremental improvement in MMSE score, for the cognitive intervention group, to be $£ 75.32$ higher (£102.21 as of 2011) than the control group (receiving the usual activities such as playing games, music, arts, and such group activities). Similar to MMSE score, for an incremental improvement in the Quality of Life-Alzheimer Disease scale the value was $£ 22.82$ ( $£ 30.96$ as of 2011).

\section{CONCLUSIONS}

To assess the current state of research on the effects of cognitive intervention in $\mathrm{AD}$, we conducted a systematic review and meta-analysis of efficacy, as well as a systematic review of feasibility and cost-effectiveness in AD. For efficacy analysis, contrasting with previous reviews, we focused exclusively on high-quality studies that only included patients diagnosed with AD that were randomly allocated 
TABLE 3. Results of Meta-Analysis of Included Studies of Cognitive Intervention in AD

\begin{tabular}{|c|c|c|c|c|c|}
\hline Cognitive Domains & $\begin{array}{l}\text { Studies } \\
(k)\end{array}$ & $\begin{array}{l}\text { Participants } \\
\text { (n) }\end{array}$ & Statistical Method & Estimated Effect (95\% CI) & $\begin{array}{l}\text { Heterogeneity } \\
\text { Index }\left(I^{2}\right)\end{array}$ \\
\hline $\begin{array}{l}\text { Global Cognitive } \\
\text { Functioning }\end{array}$ & 3 & 104 & $\begin{array}{l}\text { Mean difference (IV, fixed } \\
\text { effects, } 95 \% \text { CI) }\end{array}$ & $0.87(0.26-1.48), P=0.005$ & $14 \%$ \\
\hline $\begin{array}{l}\text { Immediate Auditory/ } \\
\text { Verbal Memory }\end{array}$ & 3 & 101 & $\begin{array}{l}\text { Standardized mean difference } \\
\text { (IV, fixed effects, } 95 \% \mathrm{CI})\end{array}$ & $-0.02(-0.41$ to 0.37$), P=0.93$ & $0 \%$ \\
\hline $\begin{array}{l}\text { Immediate Visuospatial } \\
\text { Memory }\end{array}$ & 3 & 101 & $\begin{array}{l}\text { Standardized mean difference } \\
\text { (IV, fixed effects, } 95 \% \text { CI) }\end{array}$ & $-0.13(-0.52$ to 0.26$), P=0.52$ & $0 \%$ \\
\hline $\begin{array}{l}\text { Delayed Auditory/ } \\
\text { Verbal Memory }\end{array}$ & 2 & 66 & $\begin{array}{l}\text { Standardized mean difference } \\
\text { (IV, fixed effects, } 95 \% \mathrm{CI} \text { ) }\end{array}$ & $-0.32(-0.81$ to 0.16$), P=0.19$ & $0 \%$ \\
\hline $\begin{array}{l}\text { Delayed Visuospatial } \\
\text { Memory }\end{array}$ & 2 & 66 & $\begin{array}{l}\text { Standardized mean difference } \\
\text { (IV, fixed effects, } 95 \% \text { CI) }\end{array}$ & $0.15(-0.33$ to 0.63$), P=0.54$ & $0 \%$ \\
\hline $\begin{array}{l}\text { Delayed (Verbal) } \\
\text { Memory- } \\
\text { Recognition }\end{array}$ & 2 & 64 & $\begin{array}{l}\text { Standardized mean difference } \\
\text { (IV, fixed effects, } 95 \% \mathrm{CI})\end{array}$ & $0.07(-0.42$ to 0.56$), P=0.77$ & $0 \%$ \\
\hline $\begin{array}{l}\text { Delayed (Visuospatial) } \\
\text { Memory- } \\
\text { Recognition }\end{array}$ & 1 & 29 & $\begin{array}{l}\text { Mean difference (IV, fixed } \\
\text { effects, } 95 \% \mathrm{CI})\end{array}$ & $0.20(-1.19$ to 1.59$), P=0.78$ & Not applicable \\
\hline Working Memory & 1 & 37 & $\begin{array}{l}\text { Mean difference (IV, fixed } \\
\text { effects, } 95 \% \mathrm{CI})\end{array}$ & $0.50(-1.00$ to 2.00$), P=0.51$ & Not applicable \\
\hline $\begin{array}{l}\text { Attention and } \\
\text { Concentration* }\end{array}$ & 2 & 66 & $\begin{array}{l}\text { Standardized mean difference } \\
\text { (IV, fixed effects, 95\% CI) }\end{array}$ & $-0.21(-0.70$ to 0.27$), P=0.39$ & $14 \%$ \\
\hline $\begin{array}{l}\text { Verbal Fluency- } \\
\text { Phonemic }\end{array}$ & 2 & 66 & $\begin{array}{l}\text { Mean difference (IV, fixed } \\
\text { effects, } 95 \% \text { CI) }\end{array}$ & $0.69(-4.46$ to 5.84$), P=0.79$ & $0 \%$ \\
\hline $\begin{array}{l}\text { Verbal Fluency- } \\
\text { Semantic }\end{array}$ & 2 & 72 & $\begin{array}{l}\text { Mean difference (IV, fixed } \\
\text { effects, 95\% CI) }\end{array}$ & $1.24(-1.57$ to 4.05$), P=0.39$ & $24 \%$ \\
\hline Language-Naming & 1 & 29 & $\begin{array}{l}\text { Mean difference (IV, fixed } \\
\text { effects, 95\% CI) }\end{array}$ & $-0.30(-3.90$ to 3.30$), P=0.87$ & Not applicable \\
\hline Visuospatial Abilities & 1 & 29 & $\begin{array}{l}\text { Mean difference (IV, fixed } \\
\text { effects, 95\% CI) }\end{array}$ & $-1.00(-2.91$ to 0.91$), P=0.30$ & Not applicable \\
\hline Motor Speed & 1 & 37 & $\begin{array}{l}\text { Mean difference (IV, fixed } \\
\text { effects, } 95 \% \mathrm{CI})\end{array}$ & $5.47(-1.55$ to 12.49$), P=0.13$ & Not applicable \\
\hline $\begin{array}{l}\text { Neuropsychiatric } \\
\text { Assessment* }\end{array}$ & 1 & 32 & $\begin{array}{l}\text { Mean difference (IV, fixed } \\
\text { effects, } 95 \% \mathrm{CI})\end{array}$ & $-2.06(-2.91$ to -1.21$), P<0.00001$ & Not applicable \\
\hline Depressive Symptoms* & 1 & 37 & $\begin{array}{l}\text { Mean difference (IV, fixed } \\
\text { effects, 95\% CI) }\end{array}$ & $-1.45(-4.78,1.88), P=0.39$ & Not applicable \\
\hline Quality of Life & 1 & 37 & $\begin{array}{l}\text { Mean difference (IV, fixed } \\
\text { effects, } 95 \% \mathrm{CI})\end{array}$ & $-25.30(-62.03$ to 11.43$), P=0.18$ & Not applicable \\
\hline $\begin{array}{l}\text { Activities of Daily } \\
\text { Living }\end{array}$ & 1 & 29 & $\begin{array}{l}\text { Mean difference (IV, fixed } \\
\text { effects, 95\% CI) }\end{array}$ & $-2.10(-5.70$ to 1.50$), P=0.25$ & Not applicable \\
\hline Memory Complaints* & 1 & 29 & $\begin{array}{l}\text { Mean difference (IV, fixed } \\
\text { effects, } 95 \% \mathrm{CI})\end{array}$ & $19.90(1.87-37.93), P=0.03$ & Not applicable \\
\hline
\end{tabular}

*Negative effect sizes are interpreted as favoring the experimental group (higher test scores meaning worse outcome).

$\mathrm{CI}$ indicates confidence interval; IV, inverse variance.

to either a cognitive intervention or a mock intervention group. Moreover, our study is the first in-line systematic review addressing: (1) efficacy of cognitive intervention in $\mathrm{AD}$; (2) feasibility of cognitive intervention in $\mathrm{AD}$; and (3) cost-effectiveness of cognitive intervention for people with dementia.

Overall, results demonstrate absence of effects of cognitive intervention in most of the analyzed domains and evidence of cognitive intervention effects towards improvement in global cognitive functioning as measured by MMSE. Previously, MMSE has been used as a disease progression marker. ${ }^{21}$ We could, therefore, speculate that cognitive interventions have the potential to slow disease progression to some extent. This remains to be established and explored further.

Some possible limiting factors of this work should be acknowledged. First, some issues should be kept in mind when considering MMSE results. For example, one could expect that MMSE would be rather insensitive to intervention effects over such a short period of time (5 to $10 \mathrm{wk}$ in 2 of the studies) and poor transfer of cognitive treatment could be expected, based on previous findings with healthy adults. $^{22}$ The observed change in MMSE scores could be because of several factors. For example, variations in MMSE scores do occur throughout the disease course. ${ }^{23}$ Moreover, test-retest and practice effects exist in most neuropsychological tests ${ }^{24}$ and could contribute to our observed results. Despite these criticisms, we should keep in mind that both groups would share these effects.

In addition, MMSE is a global measure (briefly tackling several domains) which has been identified to be sensitive to dementia-related cognitive decline, ${ }^{23}$ specially, episodic memory and temporal orientation items. Therefore, first, this global measure could detect/be found sensitive to (different) intervention effects (eg, tackling memory, others tackling working memory, etc.) and is also widely used in antidementia drug trials. ${ }^{17}$

Second, it is important to consider the fact that the overall effect/pooled results in Global Cognitive Functioning (as measured by MMSE) is heavily weighted (92\%) 
A

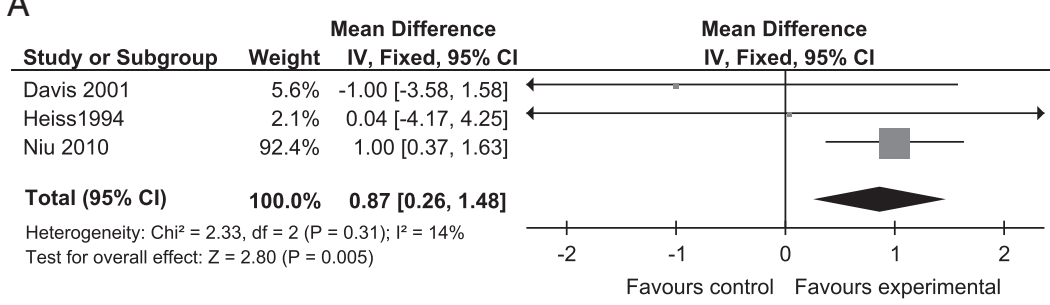

B

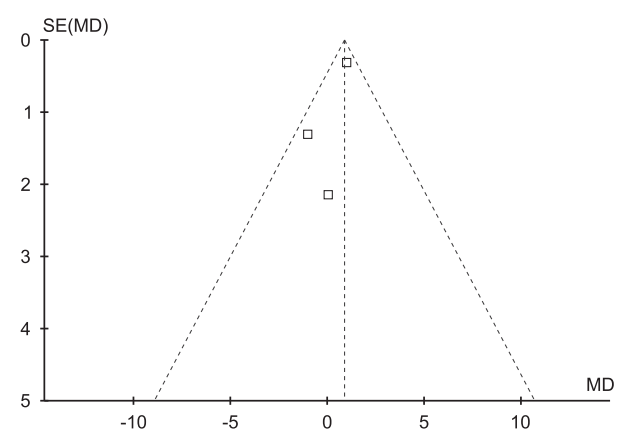

FIGURE 3. Forest plot (A) and Funnel plot (B) for global cognitive functioning (Mini-Mental Status Examination). A, Solid squares represent each of the studies included in the meta-analysis. Bigger square size reflects increasing weight of a given study for estimating the overall effect. B, Funnel plot analysis allows assessing publication bias. For each included study, the effect size was plotted against the SE.

by the study of Niu et al, ${ }^{18}$ although only 3 of the 4 studies were included in this domain. This point is also related to the point 2 , as Niu et al's ${ }^{18}$ intervention included specific orientation and episodic memory tasks that could train the participants in such sensitive items of MMSE. ${ }^{23}$
Third, this meta-analysis included cognitive interventions that varied quite widely in their focus (eg, memory training, vs. "tasks requiring executive function and working memory") and as MMSE is a global measure briefly assessing several domains/functions, it is possible to detect changes from several domains. This heterogeneity of inter-

TABLE 4. Feasibility Analysis of Included Studies

\begin{tabular}{|c|c|c|c|c|c|}
\hline Study & $\begin{array}{c}\text { Dropouts } \\
\text { After } \\
\text { Randomization } \\
\end{array}$ & $\begin{array}{l}\text { Completion } \\
\text { Rate }(\%) \\
\end{array}$ & Reasons for Withdrawal & No. Missed Interventions & Adherence Rate \\
\hline $\begin{array}{l}\text { Cahn- } \\
\text { Weiner } \\
\text { et al }{ }^{10}\end{array}$ & $5 / 34$ & 85 & $\begin{array}{l}5 \text { patients, because of } \\
\text { transportation difficulties }\end{array}$ & $\begin{array}{l}\text { Despite that in the intervention } \\
\text { group } 3 \text { people did not complete } \\
1 \text { session each, and in the control } \\
\text { group } 4 \text { people missed } 1 \text { session } \\
\text { and } 1 \text { person missed } 2 \text { sessions, the } \\
\text { mean number of sessions attended } \\
\text { by the Memory-training group } \\
(5.8 \pm 0.39) \text { and the Control group } \\
(5.6 \pm 0.61) \text { did not differ } \\
\text { significantly }[t(32)=1.0, \\
P=0.18] \text {. Total number of } \\
\text { sessions per person: } 6\end{array}$ & $\begin{array}{l}\text { Intervention group: } \\
96.7 \% \text { Control } \\
\text { group: } 92.9 \% \\
\text { Note: incomplete } \\
\text { sessions were } \\
\text { counted as missed } \\
\text { sessions } \\
\text { (conservative } \\
\text { approach) }\end{array}$ \\
\hline $\begin{array}{l}\text { Davis } \\
\text { et } \mathrm{al}^{16}\end{array}$ & $0 / 37$ & 100 & $\begin{array}{l}\text { As there was no mention of } \\
\text { dropouts, we assume } 100 \% \text { of } \\
\text { completion }\end{array}$ & $\begin{array}{l}\text { There was no mention of number of } \\
\text { missed sessions with the therapist }\end{array}$ & NA \\
\hline $\begin{array}{l}\text { Heiss } \\
\text { et } \mathrm{al}^{17}\end{array}$ & $10 / 80$ & 100 & $\begin{array}{l}\text { The authors mention that } \\
\text { dropouts were because of } \\
\text { technical insufficiencies of PET, } \\
\text { EEG data, or side effects of } \\
\text { medication }\end{array}$ & NA & NA \\
\hline Niu et al ${ }^{18}$ & $3 / 32$ & 91 & $\begin{array}{l}2 \text { patients withdrew informed } \\
\text { consents, } 1 \text { was admitted to the } \\
\text { hospital }\end{array}$ & $\begin{array}{l}\text { No missed intervention session in } \\
\text { either condition }\end{array}$ & $100 \%$ in both groups \\
\hline
\end{tabular}

EEG indicates electroencephalography; NA, data not available; PET, positron emission tomography. 
ventions might have constrained the existence of consistent specific effects (eg, on memory outcomes). The only global/ general cognitive outcome was MMSE, which could detect changes in memory from 1 study and attention from other, for example.

The underlying origin for these considerations might be the small number of studies which could be biasing the observed results (either positively and/or negatively) and also did not allow us to obtain $>2$ studies for including in meta-analysis of other domains, besides global cognitive functioning. This might be reflected in the vast majority (12 of 13) of analyzed domains being nonsignificant, pointing to a lack of specific effects.

Despite all these considerations, no evidence of publication bias was found.

Finally, to assess the efficacy of cognitive intervention in $\mathrm{AD}$, only RCTs were considered which, together with our strict criteria, limited the number of included studies. In this sense it is important to recognize that although RCTs can be considered the "gold standard" in assessing the efficacy of interventions, they present practical and methodological challenges which limit implementation related to the complexity of health care interventions, ${ }^{25}$ such as problems of randomization and concealment that can influence the results as well. It is also important to acknowledge that there are other sound methodological alternatives to between-group designs, such as single-case designs that tackle individual changes and which are recognized in establishing efficacy by organizations such as the American Psychological Association. ${ }^{26}$

Despite the small number of studies, our feasibility analysis found excellent completion and adherence rates. Although a systematic search yielded no study directly addressing cost-effectiveness of cognitive intervention with people diagnosed with AD, 1 study was found that included people with dementia (not receiving cholinesterase inhibitors treatment) living in care or community homes. In their study, Knapp et $\mathrm{al}^{20}$ pointed out a reasonable cost per incremental improvement in MMSE and Quality of Life-Alzheimer Disease scores, although no reduction in service costs or its use was found. In addition, we must consider both the traditional costs associated with dementia care and the pharmacological treatment expenses. For example, Wolstenholme et $\mathrm{al}^{27}$ estimated that a 1-point decrease in the MMSE adds $£ 56$ (£74.74 as of 2011) to direct health and social care costs over a 4-month period. Moreover, the AD2000 Collaborative Group $^{28}$ found that excluding other medication and institutionalization costs, donepezil long-term treatment group annually cost $£ 498$ more ( $£ 627.35$ as of 2011 ) compared with the placebo group. In this case, the treatment effect was an improvement of 0.83 points on the MMSE over 114 weeks, which contrasts with the relative short duration of cognitive interventions examined in the present manuscript.

In summary, in this work the available small number of studies did not allow establishing firm conclusions about the efficacy of cognitive intervention for AD patients. However, the observed results in terms of efficacy, completion, adherence, and cost-effectiveness establish the importance and need for more high-quality studies allowing to establish a thorough assessment of the efficacy of cognitive intervention, which could potentially constitute a relevant complementary therapy for dementia of the Alzheimer type.

In clinical practice, decision making concerning cognitive treatment prescription by health professionals, should involve the availability of empirically validated information weighting the efficacy, duration of effects, costs, adherence, implications for quality of life, and associated potential side effects/risks if any. In light of the present findings, despite the limited evidence (ie, few studies) cognitive intervention seems to provide modest benefits in global cognitive functioning with good completion and adherence rates. Even though so far no cost-effectiveness studies were conducted exclusively with AD patients, building on a study with people with dementia, ${ }^{20}$ one can hypothesize the cost-effective benefits of cognitive intervention in AD. In summary, given the limited efficacy of the standard pharmacological treatment, $4,5,29$ cognitive intervention should be considered as a complementary option to antidementia drugs.

Nevertheless, although the current treatment portfolio for $\mathrm{AD}$ recommends cognitive-related intervention approaches (eg, National Institute for Health and Clinical Excellence ${ }^{30}$ ), this has not been widely used by clinicians mainly because of its limited availability, perceived expensiveness, and because of the dissimilar intervention methodologies across studies.

Only a well-orchestrated effort of clinicians and researchers may provide the needed evidence for the definite assessment of the efficacy or potential side effects, such as frustration ${ }^{31}$ with cognitive intervention for $\mathrm{AD}$, leading to an evidence-based practice in the area. Therefore, patients should also be offered an option of enrollment in cognitive intervention trials in conjunction with their pharmacological treatment.

From the studies reviewed in the present manuscript, several recommendations may be drawn for the implementation of carefully designed RCTs. First, there is a need for more sensitive measures in future trials. For example, Clare et $\mathrm{al}^{9}$ showed that cognitive rehabilitation can produce significant improvements in ratings of goal performance and satisfaction, and Lowenstein et $\mathrm{al}^{32}$ showed improvements in patients' task performance after cognitive training. Therefore, neuropsychological measures should be complemented by "ecological" measures relevant to the person with $\mathrm{AD}^{9}$ and tasks assessing specific training effects. In this regard, functional neuroimaging may also be considered an additional important outcome measure for detection of potential brain changes associated with specific tasks. Presently, only 1 study ${ }^{9}$ has used functional magnetic resonance imaging as a complementary tool to assess the efficacy of a cognitive rehabilitation program.

In addition, it would be important to establish an all agreed-upon neuropsychological battery by experts in the field, with multiple versions for the prevention of test-retest effects. This battery would also facilitate an excellent comparison of outcomes among different studies. Second, other than active ingredients (eg, trained technique such as spaced retrieval, etc.), control conditions should consist of mock intervention groups that are as comparable as possible to the experimental intervention groups in all intervention variables (eg, contact with the therapist, duration, and frequency).

Finally, additional studies directly addressing the costeffectiveness of cognitive intervention, with diagnosed AD participants are warranted. Related data on "people with dementia" show adequate cost-effectiveness and, therefore, justify the need for further studies with AD participants. Future studies should also report intervention costs. Cost savings should be calculated and balanced against the potential costs of intervention. 
Two decades ago Arkin ${ }^{33(p 17)}$ stated that "the therapeutic benefit of patient and caregiver involving themselves with each other in an effortful task that addresses one of the patient's most distressing and noticeable problems has enormous face validity." Unfortunately, face validity is not synonymous with clinical efficacy. In order for cognitive intervention to move beyond the current status of limited evidence in respect to cognition, a substantial increase in high-quality studies addressing specific questions such as efficacy, feasibility, and cost-effectiveness is essential. Only by adopting such a concerted effort would we be able to move from the face validity era of cognitive intervention to evidence-based practice.

\section{REFERENCES}

1. Thies W, Bleiler L. 2011 Alzheimer's disease facts and figures. Alzheimer's Dement. 2011;7:208-244. Available at: http://www. alz.org/downloads/Facts_Figures_2011.pdf. Accessed January 30, 2012.

2. Clare L, Woods RT. Cognitive training and cognitive rehabilitation for people with early-stage Alzheimer's disease: a review. Neuropsychol Rehabil. 2004;14:385-401.

3. Backman L, Jones S, Berger AK, et al. Multiple cognitive deficits during the transition to Alzheimer's disease. J Intern Med. 2004;256:195-204.

4. Loy C, Schneider L. Galantamine for Alzheimer's disease and mild cognitive impairment. Cochrane Database Syst Rev. 2006;1:CD001747.

5. Pepeu G, Giovannini MG. Cholinesterase inhibitors and memory. Chem Biol Interact. 2010;187:403-408.

6. Olazarán J, Muñiz R, Reisberg B, et al. Benefits of cognitivemotor intervention in MCI and mild to moderate Alzheimer Disease. Neurology. 2004;63:2348-2353.

7. Clare L, Woods RT, Moniz Cook ED, et al. Cognitive rehabilitation and cognitive training for early-stage Alzheimer's disease and vascular dementia. Cochrane Database Syst Rev. 2003;4:CD003260.

8. Sitzer DI, Twamley EW, Jeste DV. Cognitive training in Alzheimer's disease: a meta-analysis of the literature. Acta Psychiatr Scand. 2006;114:75-90.

9. Clare L, Linden DE, Woods RT, et al. Goal-oriented cognitive rehabilitation for people with early-stage Alzheimer disease: a single-blind randomized controlled trial of clinical efficacy. Am J Geriatr Psychiatry. 2010;18:928-939.

10. Cahn-Weiner DA, Malloy PF, Rebok GW, et al. Results of a randomized placebo-controlled study of memory training for mildly impaired Alzheimer's disease patients. Appl Neuropsychol. 2003;10:215-223.

11. Moher D, Liberati A, Tetzlaff J, et al. Preferred reporting items for systematic reviews and meta-analyses: the PRISMA statement. PLoS Med. 2009;6:e1000097.

12. American Psychiatric Association. Diagnostic and Statistical Manual of Mental Disorders. 4th ed. Washington, DC: American Psychiatric Association; 1994.

13. McKhann G, Drachman D, Folstein M, et al. Clinical diagnosis of Alzheimer's disease: report of the NINCDSADRDA Work Group under the auspices of Department of Health and Human Services Task Force on Alzheimer's Disease. Neurology. 1984;34:939-944.

14. Review Manager (RevMan) [Computer program]. Version 5.1. Copenhagen:The Nordic Cochrane Centre, The Cochrane Collaboration, 2011.
15. Bank of England: Inflation Calculator [Bank of England web site]. Available at: http://www.bankofengland.co.uk/education/ Pages/inflation/calculator/index1.aspx. Accessed March 16, 2012.

16. Davis RN, Massman PJ, Doody RS. Cognitive intervention in Alzheimer disease: a randomized placebo-controlled study. Alzheimer Dis Assoc Disord. 2001;15:1-9.

17. Heiss WD, Kessler J, Mielke R, et al. Long-term effects of phosphatidylserine, pyritinol, and cognitive training in Alzheimer's disease. A neuropsychological, EEG, and PET investigation. Dementia. 1994;5:88-98.

18. Niu YX, Tan JP, Guan JQ, et al. Cognitive stimulation therapy in the treatment of neuropsychiatric symptoms in Alzheimer's disease: a randomized controlled trial. Clin Rehabil. 2010;24: $1102-1111$

19. Higgins JP, Thompson SG, Deeks JJ, et al. Measuring inconsistency in meta-analyses. BMJ. 2003;327:557-560.

20. Knapp M, Thorgrimsen L, Patel A, et al. Cognitive stimulation therapy for people with dementia: cost-effectiveness analysis. Br J Psychiatry. 2006;188:574-880.

21. Musicco M, Salamone G, Caltagirone C, et al. Neuropsychological predictors of rapidly progressing patients with Alzheimer's disease. Dement Geriatr Cogn Disord. 2010;30: 219-228

22. Owen AM, Hampshire A, Grahn JA, et al. Putting brain training to the test. Nature. 2010;465:775-778.

23. Small BJ, Viitanen M, Backman L. Mini-Mental State Examination item scores as predictors of Alzheimer's disease: incidence data from the Kungsholmen Project, Stockholm. J Gerontol A Biol Sci Med Sci. 1997;52:299-304.

24. Slade PD, Townes BD, Rosenbaum G, et al. The serial use of child neurocognitive tests: development versus practice effects. Psychol Assess. 2008;20:361-369.

25. Campbell M, Fitzpatrick R, Haines A, et al. Framework for design and evaluation of complex interventions to improve health. BMJ. 2000;321:694-696.

26. Chambless DL, Baker MJ, Baucom DH, et al. Update on empirically validated therapies, II. Clin Psychol. 1998;51:3-16.

27. Wolstenholme J, Fenn P, Gray A, et al. Estimating the relationship between disease progression and cost of care in dementia. Br J Psychiatr. 2002;181:36-42.

28. AD2000 Collaborative Group. Long-term donepezil treatment in 565 patients with Alzheimer's disease (AD2000): randomised double-blind trial. Lancet. 2004;363:2105-2115.

29. Hsiung GY, Feldman HH. Pharmacological treatment in moderate-to-severe Alzheimer's disease. Expert Opin Pharmacother. 2008;9:2575-2582.

30. National Institute for Health and Clinical Excellence. Dementia: Supporting People With Dementia and Their Carers in Health and Social Care. CG42. London: National Institute for Health and Clinical Excellence; 2006.

31. Small GW, Rabins PV, Barry PP, et al. Diagnosis and treatment of Alzheimer disease and related disorders: consensus statement of the American Association for Geriatric Psychiatry, the Alzheimer's Association and the American Geriatric Society. JAMA. 1997;278:1363-1371.

32. Loewenstein DA, Acevedo A, Czaja SJ, et al. Cognitive rehabilitation of mildly impaired Alzheimer disease patients on cholinesterase inhibitors. Am J Geriatr Psychiatry. 2004;12: 395-402.

33. Arkin SM. Memory training in early Alzheimer's disease: an optimistic look at the field. Am J Alzheimers Dis Other Demen. 1991;6:17-25. 